\title{
Binding of Small Molecule Drugs to Porcine Vitreous Humor
}

\section{Rimpelä, Anna-Kaisa}

2018-06

Rimpelä , A-K, Reunanen , S , Hagström , M , Kidron , H \& Urtti , A 2018 , ' Binding of Small Molecule Drugs to Porcine Vitreous Humor ' , Molecular Pharmaceutics , vol. 15 , no. 6 , pp. 2174-2179 . https://doi.org/10.1021/acs.molpharmaceut.8b00038

http://hdl.handle.net/10138/256027

https://doi.org/10.1021/acs.molpharmaceut.8b00038

unspecified

publishedVersion

Downloaded from Helda, University of Helsinki institutional repository.

This is an electronic reprint of the original article.

This reprint may differ from the original in pagination and typographic detail.

Please cite the original version. 


\title{
Binding of Small Molecule Drugs to Porcine Vitreous Humor
}

\author{
Anna-Kaisa Rimpelä, ${ }^{\dagger}$ Saku Reunanen, ${ }^{\dagger}$ Marja Hagström, ${ }^{\dagger}$ Heidi Kidron, $^{\dagger}$ and Arto Urtti* ${ }^{\dagger}, \ddagger \odot$ \\ ${ }^{\dagger}$ Centre for Drug Research, Division of Pharmaceutical Biosciences, Faculty of Pharmacy, University of Helsinki, P.O. Box 56, \\ FI-00014 Helsinki, Finland \\ ${ }^{\star}$ School of Pharmacy, University of Eastern Finland, P.O. Box 1627, FI-70211 Kuopio, Finland
}

\section{Supporting Information}

\begin{abstract}
Pharmacokinetics in the posterior eye segment has therapeutic implications due to the importance of retinal diseases in ophthalmology. In principle, drug binding to the components of the vitreous, such as proteins, collagen, or glycosaminoglycans, could prolong ocular drug retention and modify levels of pharmacologically active free drug in the posterior eye segment. Since drug binding in the vitreous has been investigated only sparsely, we studied vitreal drug binding of 35 clinical small molecule drugs. Isolated homogenized porcine vitreous and the drugs were placed in a two-

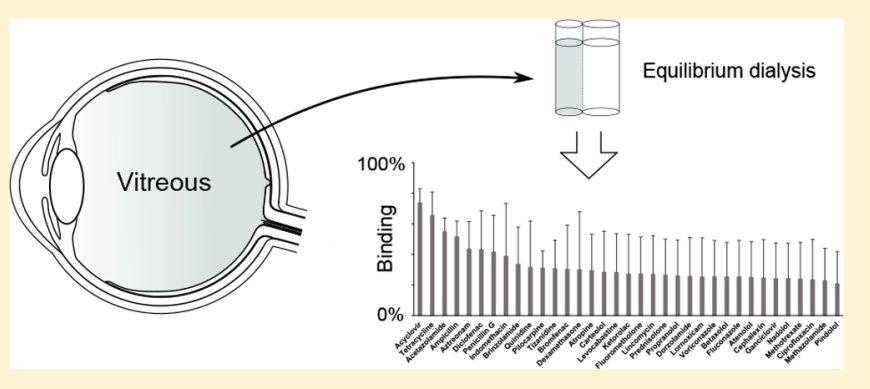
compartment dialysis system that was used to separate the bound and unbound drug. Free drug concentrations and binding percentages were quantitated using LC-MS/MS. Drug binding levels varied between 21 and $74 \%$ in the fresh vitreous and 0 and $64 \%$ in the frozen vitreous. The vitreal binding percentages did not correlate with those in plasma. Our data-based pharmacokinetic simulations suggest that vitreal binding of small molecule drugs has only a modest influence on the AUC of free drug or drug half-life in the vitreous. Therefore, it is likely that vitreal binding is not a major reason for interindividual variability in ocular drug responses or drug-drug interactions.
\end{abstract}

KEYWORDS: retinal drug delivery, vitreous, vitreal binding, ocular pharmacokinetics, drug binding

\section{INTRODUCTION}

Posterior tissues of the eye are critically important for the vision. Therefore, drug treatment of the vitreous, retina, choroid, and optic nerve is important in many conditions that endanger the eyesight. ${ }^{1}$ These conditions include, for example, infections, inflammatory conditions, neo-vascularization, cell proliferation, retinal degenerations, and ocular malignancies. Drug delivery to the posterior segment of the eye is usually accomplished by intravitreal injections, other local ocular injections, or systemic delivery. The drug permeability in blood ocular barriers has a major impact on the drug clearance from the vitreous to the blood circulation and, therefore, it is the main determinant of the half-life of intravitreally injected drugs. ${ }^{2,3}$ In addition, drug distribution from the plasma to the tissues is affected by drug permeability across the tissue-blood barriers and protein binding of the drug in the plasma and tissues. Accordingly, drug distribution from the blood circulation to the vitreous in rabbits has been successfully predicted based on the drug binding to the plasma proteins and the distribution clearance across the blood ocular barriers. ${ }^{4}$ The extent of the drug binding in the vitreous, however, was not included in this model, and the importance of vitreal binding is still unclear.

Vitreous is the largest anatomical compartment in the eye with volumes of 1.5 and $4 \mathrm{~mL}$ in rabbits and humans, respectively. ${ }^{5}$ The main components of the human vitreous, in addition to a water content of $98-99.7 \%$, are proteins and hyaluronic acid. ${ }^{6}$ In addition to structural collagens, the vitreous contains nonstructural proteins, mainly albumin. Estimates of the total protein content in the vitreous vary between 0.5 and 5 $\mathrm{mg} / \mathrm{mL},{ }^{7-10}$ but are generally assumed to be between 0.5 and $1.5 \mathrm{mg} / \mathrm{mL} .{ }^{11}$ Of this amount, $60-70 \%$ is albumin. ${ }^{8,10}$ Intravitreally injected small molecular drugs are often rapidly cleared from the vitreous at half-lives less than $10 \mathrm{~h}^{3}$ It is believed that the large range of clearance values (about 50-fold) for small molecule drugs is due to the differences in their permeability across the blood ocular barriers; high permeability indicating rapid drug elimination from the vitreous. In principle, these differences could also be due to major differences in binding to the proteins and other vitreal components. Protein concentration $(<5 \mathrm{mg} / \mathrm{mL})$ and the number of proteins $(\approx 1300)$ in the vitreous are less than in plasma (concentration of $60-80 \mathrm{mg} / \mathrm{mL} ; 3000$ protein species $),{ }^{8}$ but the binding could also occur with other vitreal components, such as hyaluronic acid, other glycosaminoglycans, and collagen. The rate of molecular diffusion in the vitreous depends on the size and charge of the diffusing compound; therefore, increased size and binding to vitreal components may reduce the mobility and increase the half-life

Received: January 13, 2018

Revised: March 14, 2018

Accepted: April 12, 2018

Published: April 12, 2018 
of the drug. ${ }^{2,11,12}$ Recently, Fuchs and Igney ${ }^{13}$ showed that the half-life of a nanobody in the rabbit vitreous was prolonged 3fold when the compound was coinjected with human serum albumin. However, binding interactions of small molecule drugs with the vitreous have not been studied. Extensive drug binding to the macromolecules in the vitreous should prolong the vitreal elimination half-life, because the clearance of the proteins from the vitreous is much slower than the elimination of the small molecule compounds. ${ }^{3}$

Drug binding to proteins or other components in the vitreous may be an important factor in ocular pharmacokinetics and pharmacodynamics. It is expected to increase drug distribution from the blood circulation to the eye based on the distribution equilibrium. Ocular elimination of intravitreally administered drugs depends on their molecular size, with the half-lives of protein drugs being in the range of 3-10 days. ${ }^{2,11}$ Binding to proteins and other vitreal macromolecules should prolong the drug retention and duration of action in the vitreous. Protein binding might also lead to pharmacokinetic changes in the diseased eye, when the vitreous composition or vitreal protein concentration is affected.

The potential importance of the protein binding of small molecule drugs in the vitreous is still unknown, and the binding of drugs to the vitreous humor has only been described in two conference presentations. ${ }^{14,15}$ Therefore, we carried out a systematic study to investigate the binding of 35 small molecule ocular drugs to the isolated porcine vitreous humor. The drugs were chosen to represent a wide range of physicochemical parameters, to be able to cover a variety of molecular properties that could cause vitreal binding. The equilibrium dialysis method was used in our study because it allows easy separation of bound and free drug. Since vitreal binding of drugs is so poorly known, we used the fraction bound at the equilibrium as the end-point. We show that vitreal binding of small molecular weight drugs is relatively low and not a significant factor in ocular pharmacokinetics.

\section{EXPERIMENTAL SECTION}

Vitreous Humor. Fresh porcine eyes were obtained from a local slaughterhouse (HKScan, Forssa, Finland). The eyes were kept in ice during transportation. Extra tissues from the ocular surfaces were dissected and removed. The eyes were soaked in ethanol for $20 \mathrm{~s}$ and then placed in Dulbecco's phosphate buffered saline (DPBS) (without $\mathrm{MgCl}_{2}$ and $\mathrm{CaCl}_{2}$, Gibco, Thermo Fisher Scientific, Waltham, MA, USA). To avoid contamination from cellular debris and melanin, approximately $1 \mathrm{~mL}$ of vitreous humor was collected per one eye with a syringe through an incision done about $1 \mathrm{~cm}$ posterior to the iris. Thereafter, the vitreous humor was homogenized under ice and centrifuged at $+4{ }^{\circ} \mathrm{C}$ for $60 \mathrm{~min}$ at $3200 \mathrm{~g}$. The homogenized vitreous humor was filtered through filters of 0.45 and $0.22 \mu \mathrm{m}$. The vitreous was used for the binding experiments after it was stored at $+4{ }^{\circ} \mathrm{C}$ overnight (fresh vitreous) or at $-80{ }^{\circ} \mathrm{C}$ (frozen vitreous, thawed before the experiment). The vitreous from different eyes was pooled together, and the same vitreous isolate was used throughout the study.

Drugs. In total 35 drugs were used in the study as a cassette mixture. The mixture was the same as used by Pelkonen et al. ${ }^{16}$ (Table 1), and the drugs were dissolved at $1 \mathrm{mg} / \mathrm{mL}$ in DMSO or phosphate buffer as presented in their study. Before the study, the $1 \mathrm{mg} / \mathrm{mL}$ drug cassette was diluted to a

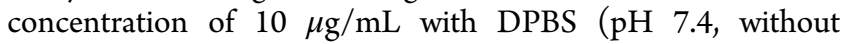

Table 1. Cassette of Drugs Used in the Study ${ }^{a}$

$\begin{array}{llll}\text { acetazolamide } & \text { carteolol } & \text { indomethacin } & \text { pilocarpine } \\ \text { acyclovir } & \text { cephalexin } & \text { ketorolac } & \text { pindolol } \\ \text { ampicillin } & \text { ciprofloxacin } & \text { levocabastine } & \text { prednisolone } \\ \text { atenolol } & \text { dexamethasone } & \text { lincomycin } & \text { propanolol } \\ \text { atropine } & \text { diclofenac } & \text { lornoxicam } & \text { quinidine } \\ \text { aztreonam } & \text { dorzolamide } & \text { methazolamide } & \text { tetracycline } \\ \text { betaxolol } & \text { fluconazol } & \text { methotrexate } & \text { tizanidine } \\ \text { brinzolamide } & \text { fluorometholone } & \text { nadolol } & \text { voriconazole } \\ \text { bromfenac } & \text { ganciclovir } & \text { penicillin G } & \end{array}$

${ }^{a_{\text {The }}}$ mixture is the same as in Pelkonen et al. ${ }^{16}$

$\mathrm{MgCl}_{2}$ and $\mathrm{CaCl}_{2}$, Gibco, Thermo Fisher Scientific). This concentration was further diluted to $100 \mathrm{ng} / \mathrm{mL}$ in the study setting. In addition to the cassette experiments, three compounds (indomethacin, prednisolone, and propranolol) were tested as individual compounds using dilutions similar to the ones described above.

Binding Study. Rapid equilibrium dialysis (RED) inserts (\#89809, Thermo Fisher Scientific) were used in the binding experiments. The donor compartment contained $195 \mu \mathrm{L}$ of homogenized vitreous (DPBS instead of vitreous in the control sample) and $5.5 \mu \mathrm{L}$ of the cassette mixture. The receiver compartment contained $350 \mu \mathrm{L}$ of DPBS ( $\mathrm{pH} 7.4$ ). The final drug concentration in the total volume of the RED insert was $100 \mathrm{ng} / \mathrm{mL}$. The inserts were incubated at $+37{ }^{\circ} \mathrm{C}$ during the binding study and shaken at $225 \mathrm{rpm}$. Samples of $30 \mu \mathrm{L}$ were withdrawn from the receiver compartment at $0,6,8$, and $24 \mathrm{~h}$, and equivalent volumes of DPBS were placed in the chamber. The samples were immediately frozen and stored at $-80{ }^{\circ} \mathrm{C}$ until analyzed. The experiments were done in triplicates (both controls and experiments with the vitreous).

Analytical Methods. Concentrations of the compounds were determined using a LC-MS/MS technique based on a previously described method. ${ }^{17} \mathrm{~A}$ minimum of six concentrations of standards were used for the quantitation of each drug. Ganciclovir D5, atropine D5, atenolol D7, lornoxicam D4, indomethacin D4, lincomycin D3, fluconazole D4, dexamethasone D5, cephalexin D5, and methotrexate D3 were tested as internal standards, but, in the final results, dexamethasone D5 and cephalexin D5 were left out due to low peak intensity.

Liquid chromatography separations were carried out using Waters Acquity UPLC instrument (Waters, MA, USA) coupled with an Agilent Poroshell 120 SB-C18 $(2.7 \mu \mathrm{m}, 2.1 \times 50 \mathrm{~mm})$ column (Agilent Technologies, Inc., Wilmington, DE, USA) at $50{ }^{\circ} \mathrm{C}$. The mobile phase consisted of $0.1 \%$ of formic acid in ultrapure water (A) and 100\% of LC-MS grade acetonitrile (B). The gradient elution started with $2 \%$ of $\mathrm{B}$ at $0-0.5 \mathrm{~min}$, continued with $2-100 \% \mathrm{~B}$ at $0.5-7 \mathrm{~min}, 100 \% \mathrm{~B}$ at $7-12 \mathrm{~min}$, a reduction to $2 \% \mathrm{~B}$ at $12-12.2 \mathrm{~min}$, and then $2 \% \mathrm{~B}$ at $12.2-14$ min for equilibration of the column. The flow-rate was $0.3 \mathrm{~mL} /$ min, and the injection volume was $0.5 \mu \mathrm{L}$. After each sample was injected, two wash injections of isopropanol were made to prevent carry-over.

Mass spectral experiments were carried out using a Xevo triple quadrupole mass spectrometer (TQ-S) equipped with an electrospray ionization (ESI) source (Waters). The ESI source was operated in the positive ionization mode. The optimal source parameters were as follows: capillary voltage of $3.5 \mathrm{kV}$, cone voltage of $2 \mathrm{~V}$, source temperature of $150{ }^{\circ} \mathrm{C}$, and desolvation temperature of $600{ }^{\circ} \mathrm{C}$. Nitrogen was used as a desolvation gas $\left(900 \mathrm{~L} \mathrm{~h}^{-1}\right)$ and a cone gas $\left(150 \mathrm{~L} \mathrm{~h}^{-1}\right)$. The 


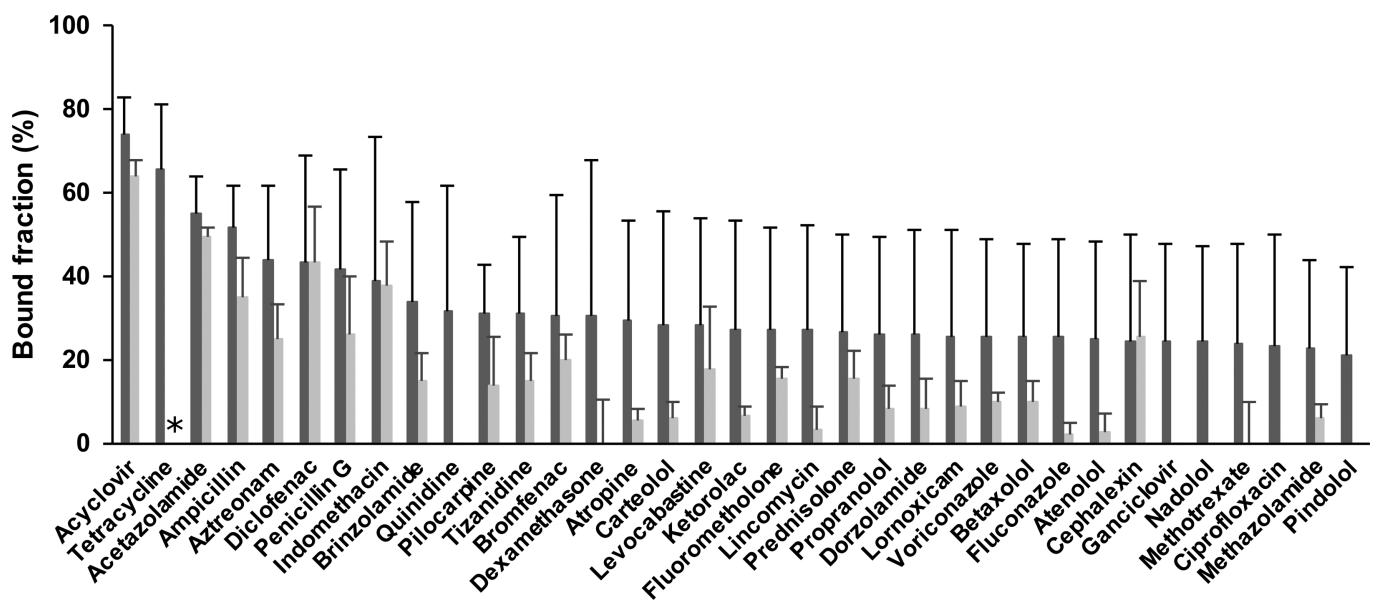

Figure 1. Undiluted binding percentages to the fresh (dark gray) and frozen (light gray) vitreous. * There are no results for tetracycline in the frozen vitreous.

multiple reaction monitoring (MRM) mode was employed for quantification. The parameters for each compound are listed in Table S1 as well as the precursor and fragment ions and internal standards. The resulting data were analyzed with Waters MassLynx software. Tetracycline was left out of the result analysis in the frozen vitreous due to a large variation in the concentration of replicate samples.

Samples from the individually studied compounds (indomethacin, prednisolone, and propranolol) were analyzed with UPLC (Acquity UPLC, Waters, Milford, MA, USA) with UV detection (Photodiode Array Detector, Waters). The separation was carried out on a Luna Omega Polar C-18 (1.6 $\mu \mathrm{m}, 2.1 \times 50$ $\mathrm{mm}$ ) column (Phenomenex, Torrance, CA, USA) at $30{ }^{\circ} \mathrm{C}$. The injection volume was $10 \mu \mathrm{L}$, and the flow rate $500 \mu \mathrm{L} / \mathrm{min}$. A gradient mode was used for all of the compounds with a mobile phase consisting of $15 \mathrm{mM}$ phosphate buffer (A) and acetonitrile (B) (0 min 70\% A/30\% B, 2 min 20\% A/80\% B).

Data Analysis. The level of drug binding was determined based on the 8-h data (equilibrium had been reached, data not shown). Binding levels in the setting $\left(f_{\mathrm{b} \text {,in vitro }}\right)$ were calculated using eq 1 :

$$
f_{\mathrm{b}, \text { in vitro }}=\left(C_{\mathrm{DPBS}}-C_{\text {vitr }}\right) / C_{\mathrm{DPBS}}
$$

where $C_{\mathrm{DPBS}}$ is the drug concentration in the receiver compartment of the control experiment, and $C_{\text {vitr }}$ is the drug concentration in the receiver compartment of the experiment with the vitreous humor.

As dilution is known to cause an increase in the unbound fraction, the dilution caused by the in vitro setting was taken into account according to eq $2 .{ }^{18}$

$$
\text { Undiluted } f_{\mathrm{u}}=\frac{1 / D}{\left(\left(1 / f_{\mathrm{u}, \text { in vitro }}-1\right)+1 / D\right.}
$$

where $D$ is the dilution factor (i.e., the ratio of dilution, $550 \mu \mathrm{L}$ (total insert volume) $/ 195 \mu \mathrm{L}$ (vitreous in the donor compartment $)=2.82)$, and $f_{\text {u,in vitro }}$ is the unbound fraction in the in vitro setting $\left(f_{\mathrm{u} \text {,in vitro }}=1-f_{\mathrm{b} \text {,in vitro }}\right)$.

Simulation Model. Intravitreal pharmacokinetics were simulated after an intravitreal injection with the binding results obtained from this study (Undiluted $f_{\mathrm{u}}$ ). The fraction bound was assumed to be constant at all of the drug concentrations. High and low intravitreal clearance values $(0.5$ and $0.1 \mathrm{~mL} / \mathrm{h}$, respectively) were used for the unbound compound, and the bound compound was assumed to have a typical vitreal clearance of a protein $(0.01 \mathrm{~mL} / \mathrm{h})$. The simulations assumed a volume of distribution of $4 \mathrm{~mL}$ (human vitreal volume). At this volume, the half-lives of high and low clearance compounds (without binding) and protein bound compounds are 5.5, 28, and $280 \mathrm{~h}$, respectively. The dissociation rate of drug from the binding site was assumed to be $0.1 \mathrm{~min}^{-1}$ (the range from 0.04 $\mathrm{min}^{-1}$ to $0.04 \mathrm{~s}^{-119}$ had a minimal effect on the results). The simulations were carried out using Stella Professional software (Isee Systems, Lebanon, NH, USA).

\section{RESULTS}

Binding to the fresh vitreous ranged from 9 to $50 \%$ and to the frozen vitreous from 0 to $39 \%$ in the in vitro conditions of this study (Figure S1, Supporting Information). The results taking into account the dilution in the in vitro setting ranged from 21 to $74 \%$ in the fresh vitreous (Figure 1) and from 0 to $64 \%$ in the frozen vitreous (Figure S1).

Binding was similar in the frozen and the fresh vitreous (Figure 1, Figures S1 and S2), suggesting that frozen vitreous can be used in the binding studies. The only significant difference was seen in the case of ampicillin $(P<0.046)$. The tests with the individual compounds (indomethacin, prednisolone, and propranolol) did not show differences in the binding levels when compared to the results with the drug mixture (Figure S3).

On the basis of the simulations, binding in the vitreous is expected to have a modest impact on the vitreal exposure of the unbound drug (area under the vitreal concentration curve, AUC) even at the highest binding levels of $64 \%$ (frozen vitreous) and $74 \%$ (fresh vitreous) (Table 2). Although the elimination half-life in the vitreous increased with increased binding, changes in the AUC of the free drug were small (Table 2).

We compared the results of vitreal binding with drug binding to plasma proteins (Figure 2). These two factors did not correlate with each other.

\section{DISCUSSION}

We showed that drug binding in the vitreous humor is generally lower than that in the plasma, and the binding levels are not correlated (Figure 2). This might reflect the lower protein concentrations in the vitreous. At equilibrium, higher binding in 
Table 2. Effect of Binding on the AUC (Free Drug) and Elimination Half-Life in the Vitreous for a Low and Fast Clearance Drug ${ }^{a}$

\begin{tabular}{ccc}
\multicolumn{4}{c}{ low clearance, CL $0.1 \mathrm{~mL} / \mathrm{h}$} \\
\hline bound \% & AUC (\% of AUC without binding) & $t_{1 / 2}(\mathrm{~h})$ \\
\hline 0 & 100 & 28 \\
20 & 98 & 34 \\
40 & 94 & 43 \\
50 & 91 & 50 \\
64 & 84 & 65 \\
74 & 75 & 83 \\
& fast clearance, CL $0.5 \mathrm{~mL} / \mathrm{h}$ & \\
\hline bound \% & AUC (\% of AUC without binding) & $t_{1 / 2}(\mathrm{~h})$ \\
0 & 100 & 5.5 \\
20 & 99.5 & 6.9 \\
40 & 99 & 9.2 \\
50 & 98 & 11 \\
64 & 97 & 15 \\
74 & 95 & 20
\end{tabular}

${ }^{a}$ The highest binding percentage in the frozen vitreous was $64 \%$ and in the fresh vitreous $74 \%$.

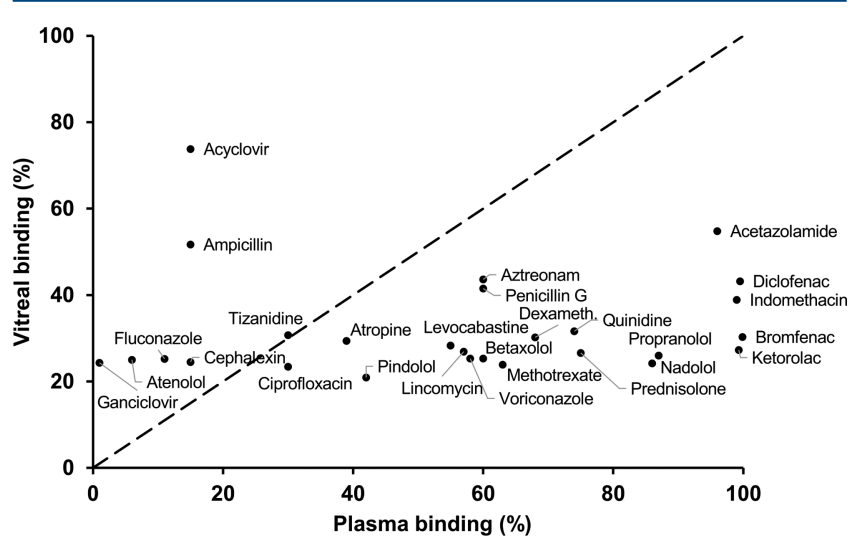

Figure 2. Comparison of the plasma protein binding ${ }^{20,21}$ and vitreal binding (fresh vitreous) of 27 drugs included in the cassette mix. The coefficient of determination $\left(R^{2}\right)$ between plasma and vitreal binding is 0.00032 .

the plasma is expected to lead to higher drug levels in the plasma than in the vitreous. The simulation model showed that vitreal binding modulates drug exposure (elimination half-life, AUC) in the vitreous (Table 2), but binding has a relatively small impact and does not explain the large differences in the vitreal clearance of small molecules. ${ }^{3}$ This conclusion is also supported by the results of a recent study where the prediction of drug distribution from blood circulation to the vitreous was successful without taking into account the vitreal binding of the drugs. ${ }^{4}$

Even though most drugs showed less binding in the vitreous than in the plasma, a few drugs had higher (acyclovir and ampicillin) or similar binding in the vitreous compared to the plasma (Figure 2). This suggests that they may bind to components in the vitreous other than the common plasma proteins, albumin and $\alpha$-1-acid glycoprotein. Because the protein content of the vitreous is considerably lower than that of the plasma $(0.5-1.5 \mathrm{vs} 60-80 \mathrm{mg} / \mathrm{mL}$, respectively), the higher or even similar binding in the vitreous compared to the plasma is most likely caused by binding to vitreal components other than the proteins. The negatively charged hyaluronic acid, the most abundant glycosaminoglycan in the vitreous, is a prominent candidate for a nonprotein binding component.

Drug binding to plasma proteins is susceptible to drug-drug interactions, as two drugs may compete for the same binding site. Displacement of the "victim" drug from albumin or $\alpha-1$ acid glycoprotein may lead to increased free drug concentration and more intense pharmacological effects. ${ }^{22}$ The relative change in the unbound drug concentration is seen if the "victim" drug has high levels of protein binding. For example, if the binding level is $99 \%$, displacement of $10 \%$ increases the unbound percentage from $1 \%$ to $11 \%$, i.e., a 10 -fold change in the unbound concentration. Changes in the unbound drug levels are insignificant if the protein binding is, for example, only $30 \%$; displacement of $10 \%$ results in a shift from 70 to $73 \%$, i.e. practically no change in the unbound concentration. Thus, considering the binding levels (0-74\%), competition of several drugs for binding sites in the vitreous is most likely an insignificant factor in ocular pharmacology. The lack of competition in the experiments in this study (Figure S3) is in line with this conclusion.

Since this study was carried out using vitreous from porcine eyes, drawing conclusions about drug binding in the human vitreous should be done cautiously. The porcine vitreous contains slightly lower levels of protein and hyaluronic acid than those of the human vitreous, and the hyaluronic acid in the porcine vitreous has a lower molecular weight. ${ }^{23}$ Nevertheless, considering that the protein levels in the human vitreous are low and the predominant nonprotein component of both human and porcine vitreous is hyaluronic acid, ${ }^{24}$ it is likely that the binding levels are also low in human eyes. The impact of the disease states in human eyes is another complicating factor that should be considered. Recently, we thoroughly analyzed the literature of the disease state pharmacokinetics in the vitreous and concluded that the impact of disease states on pharmacokinetics in the posterior eye segment is surprisingly minor. ${ }^{11}$ This analysis included various disease state models, in which also protein levels of the vitreous may have changed. Even the liquefaction of the vitreous happening mainly due to aging does not considerably affect the barrier functions of the vitreous for small molecules, although some differences in diffusion have been seen. ${ }^{11,25,26}$ In liquefaction, the vitreous loses its gel-like appearance, and the ratio of liquid to gel can increase from $1: 4$ to $1: 1 .^{24,26}$ Even though the barrier functions are not affected, the binding could change due to a change in the composition of the structural collagens and hyaluronic acid. This in turn could affect the clearance of the drugs. As the binding to the vitreous was low, the changes in binding due to liquefaction, while possible, are expected to be small.

In addition to using porcine vitreous instead of human, the vitreous was homogenized before studying the binding. Homogenization was carried out to ease the experimental procedure and ensure the uniform composition of the vitreous throughout the study. When extracted from the porcine eye, the vitreous is not a uniform tissue but has structurally different segments (liquid and gel). It also contains parts of the surrounding ocular tissues, such as cellular debris and melanin. These components can interfere with the binding, especially the melanin, which is known to bind certain drugs extensively. ${ }^{27}$ To avoid contamination by other tissues, we isolated the vitreous by withdrawing it with a syringe from an opening cut 
approximately $1 \mathrm{~cm}$ posterior to the iris. This approach, together with the subsequent homogenization and filtration of the isolate, is efficient in avoiding contamination but can change the structure of the vitreous, since mainly the soluble components of the vitreous are present in the final product. The soluble proteins of the vitreous are not expected to be affected considerably by the isolation procedure, but the larger macromolecules, such as the glycosaminoglycans and collagen, can be eroded or left on the filter or pellet and not included in the studied isolate. These changes might affect the binding results of the study, but as some of the studied drugs bound more than can be expected based on protein binding, it is likely that other binding components, such as hyaluronic acid, are present in the vitreous isolate.

The biochemical composition of the vitreous is not uniform in the eye. ${ }^{6,28}$ Thus, the drug binding could vary in different parts of the vitreous. Hyaluronic acid levels are the highest in the posterior cortex of the vitreous and the lowest in the anterior vitreous. $^{28,29}$ Collagen concentration is the lowest in the central vitreous and increases toward the basal vitreous (anterior vitreous) and the cortex. Drug binding in the approximately $100-300-\mu \mathrm{m}$ thick vitreous $\operatorname{cortex}^{28}$ would be the most relevant for drug treatment of the posterior tissues of the eye, such as the retina and choroid. In the cortical vitreous, the concentrations of both hyaluronic acid and collagen are higher than in other parts of the vitreous (high collagen also in the basal vitreous), which may cause higher drug binding than in the pooled vitreous of this binding study. Whether this has an effect on drug distribution in the vitreous is more difficult to study, as isolating only the cortex of the vitreous would be difficult.

Treating diseases of the posterior segment of the eye is generally accomplished by intravitreal or other local ocular injections. ${ }^{1}$ These can cause high local concentrations of the drug, and the therapeutic window of ocular drugs needs to be relatively wide. The vitreal binding range obtained in this study was narrow, with unbound fractions varying from 26 to $100 \%$. Thus, for the studied drugs, vitreal binding is not expected to have much impact on the efficacy of these drugs in ocular tissues.

Ocular diseases can affect the composition of the vitreous humor, but these effects are not well-known, and the extent of these changes may depend on the disease state. Disease states do not always result in significant changes in the vitreal protein levels. For example, the impact of diabetic retinopathy on protein concentrations in the vitreous was relatively minor. ${ }^{7}$ Comparative literature analyses of intravitreal drug clearance in healthy rabbits, diseased rabbits, and human patients suggest that the diseases have a surprisingly small impact on vitreal drug clearance. ${ }^{5,11}$ We do not know the impact of different disease states on the vitreal drug binding, but most likely these effects are not important, because (1) only a major increase in binding (up to $>90 \%$ levels from current low levels) would result in significant pharmacokinetic impact, and (2) increased protein levels in the vitreous are associated with increased permeability of the blood-retina barrier that increases clearance, while protein binding tends to decrease it.Finally, the studied drugs represent a wide range of physicochemical properties with $\log D_{7.4}$ values varying from -5.1 to 4.2 and polar surface area from 4.1 to $330 \AA \AA^{16,17}$ Therefore, it is likely that the variety of molecules studied here covers most of the vitreal binding range expected for small molecules, but it is still possible that some other molecule binds more extensively to the vitreous. Overall, we can conclude that binding levels of drugs in the vitreous seem to be relatively low, with most of the drug being in the free unbound form. The pharmacological importance of vitreal binding is only modest, far less than the impact of other factors, such as the permeability in the blood retina barriers.

\section{ASSOCIATED CONTENT}

\section{S Supporting Information}

The Supporting Information is available free of charge on the ACS Publications website at DOI: 10.1021/acs.molpharmaceut.8b00038.

Binding percentages to frozen and fresh vitreous, comparison of binding in the fresh vs frozen vitreous, comparison of individual and cassette results, and details of the mass spectrometric method (PDF)

\section{AUTHOR INFORMATION}

\section{Corresponding Author}

*E-mail: arto.urtti@helsinki.fi; Telephone: +35840 5402279. ORCID $\odot$

Arto Urtti: 0000-0001-6064-3102

\section{Notes}

The authors declare no competing financial interest.

\section{ACKNOWLEDGMENTS}

This study was supported by the Academy of Finland (268868, 257786), Sigrid Juselius Foundation, and University of Helsinki Doctoral Programme in Drug Research. The study utilized the Biocenter Finland infrastructure in Drug Discovery and Chemical Biology. We acknowledge Timo Oksanen for conducting the UPLC analysis.

\section{ABBREVIATIONS}

AUC, area under the curve; CL, clearance; DMSO, dimethyl sulfoxide; DPBS, Dulbecco's phosphate buffered saline; ESI, electrospray ionization; LC-MS/MS, liquid chromatographytandem mass spectrometry; RED, rapid equilibrium dialysis; UPLC, ultraperfomance liquid chromatography; UV, ultraviolet

\section{REFERENCES}

(1) del Amo, E. M.; Urtti, A. Current and Future Ophthalmic Drug Delivery Systems. A Shift to the Posterior Segment. Drug Discovery Today 2008, 13 (3-4), 135-143.

(2) Maurice, D. M.; Mishima, S. Ocular Pharmacology. In Handbook of Experimental Pharmacology; Sears, M., Ed.; Springer-Verlag: BerlinHeidelberg, 1984; Vol. 69, pp 16-119.

(3) del Amo, E. M.; Vellonen, K. S.; Kidron, H.; Urtti, A. Intravitreal Clearance and Volume of Distribution of Compounds in Rabbits: In Silico Prediction and Pharmacokinetic Simulations for Drug Development. Eur. J. Pharm. Biopharm. 2015, 95, 215-226.

(4) Vellonen, K.-S.; Soini, E.-M.; del Amo, E. M.; Urtti, A. Prediction of Ocular Drug Distribution from Systemic Blood Circulation. Mol. Pharmaceutics 2016, 13 (9), 2906-2911.

(5) del Amo, E. M.; Urtti, A. Rabbit as an Animal Model for Intravitreal Pharmacokinetics: Clinical Predictability and Quality of the Published Data. Exp. Eye Res. 2015, 137, 111-124.

(6) Le Goff, M. M.; Bishop, P. N. Adult Vitreous Structure and Postnatal Changes. Eye (London, U. K.) 2008, 22 (10), 1214-1222.

(7) Loukovaara, S.; Nurkkala, H. L.; Tamene, F.; Gucciardo, E.; Liu, X.; Repo, P.; Lehti, K.; Varjosalo, M. Quantitative Proteomics Analysis of Vitreous Humor from Diabetic Retinopathy Patients. J. Proteome Res. 2015, 14 (12), 5131-5143. 
(8) Angi, M.; Kalirai, H.; Coupland, S. E.; Damato, B. E.; Semeraro, F.; Romano, M. R. Proteomic Analyses of the Vitreous Humour. Mediators Inflammation 2012, 2012, 1-7.

(9) Theocharis, A. D.; Papageorgakopoulou, N.; Feretis, E.; Theocharis, D. A. Occurrence and Structural Characterization of Versican-like Proteoglycan in Human Vitreous. Biochimie 2002, 84 (12), 1235-1241.

(10) Ulrich, J. N.; Spannagl, M.; Kampik, A.; Gandorfer, A. Components of the Fibrinolytic System in the Vitreous Body in Patients with Vitreoretinal Disorders. Clin. Experiment. Ophthalmol. 2008, 36 (5), 431-436.

(11) del Amo, E. M.; Rimpelä, A.-K.; Heikkinen, E.; Kari, O. K.; Ramsay, E.; Lajunen, T.; Schmitt, M.; Pelkonen, L.; Bhattacharya, M.; Richardson, D.; Subrizi, A.; Turunen, T.; Reinisalo, M.; Itkonen, J.; Toropainen, E.; Casteleijn, M.; Kidron, H.; Antopolsky, M.; Vellonen, K. S.; Ruponen, M.; Urtti, A. Pharmacokinetic Aspects of Retinal Drug Delivery. Prog. Retinal Eye Res. 2017, 57, 134-185.

(12) Shatz, W.; Hass, P. E.; Mathieu, M.; Kim, H. S.; Leach, K.; Zhou, M.; Crawford, Y.; Shen, A.; Wang, K.; Chang, D. P.; Maia, M.; Crowell, S. R.; Dickmann, L.; Scheer, J. M.; Kelley, R. F. Contribution of Antibody Hydrodynamic Size to Vitreal Clearance Revealed through Rabbit Studies Using a Species-Matched Fab. Mol. Pharmaceutics 2016, 13 (9), 2996-3003.

(13) Fuchs, H.; Igney, F. Binding to Ocular Albumin as a Half-Life Extension Principle for Intravitreally Injected Drugs: Evidence from Mechanistic Rat and Rabbit Studies. J. Ocul. Pharmacol. Ther. 2017, 33 (2), 115-122.

(14) Schauersberger, J.; Jager, W. In-Vitro Investigation of the Protein Binding of Different Antibiotics in the Human Vitreous. Investig. Ophthalmol. Vis. Sci. 2002, 43 (13), 1853-1853.

(15) Petternel, V.; Krepler, K.; Schauersberger, J.; Wedrich, A. Fosfomycin in Human Vitreous: - In-vitro Investigation of the Protein Binding of Fosfomycin in Human Vitreous - Fosfomycin Levels in the Vitreous Cavity after Intravenous Administration. Investig. Ophthalmol. Vis. Sci. 2004, 45 (13), 4930 ARVO Abstract.

(16) Pelkonen, L.; Tengvall-Unadike, U.; Ruponen, M.; Kidron, H.; del Amo, E. M.; Reinisalo, M.; Urtti, A. Melanin Binding Study of Clinical Drugs with Cassette Dosing and Rapid Equilibrium Dialysis Inserts. Eur. J. Pharm. Sci. 2017, 109, 162-168.

(17) Ramsay, E.; Ruponen, M.; Picardat, T.; Tengvall, U.; Tuomainen, M.; Auriola, S.; Toropainen, E.; Urtti, A.; del Amo, E. M. Impact of Chemical Structure on Conjunctival Drug Permeability: Adopting Porcine Conjunctiva and Cassette Dosing for Construction of In Silico Model. J. Pharm. Sci. 2017, 106 (9), 2463-2471.

(18) Kalvass, J. C.; Maurer, T. S. Influence of Nonspecific Brain and Plasma Binding on CNS Exposure: Implications for Rational Drug Discovery. Biopharm. Drug Dispos. 2002, 23 (8), 327-338.

(19) Berezhkovskiy, L. M. Determination of Hepatic Clearance with the Account of Drug-Protein Binding Kinetics. J. Pharm. Sci. 2012, 101 (10), 3936-3945.

(20) Obach, R. S.; Lombardo, F.; Waters, N. J. Trend Analysis of a Database of Intravenous Pharmacokinetic Parameters in Human for 670 Drug Compounds. Drug Metab. Dispos. 2008, 36 (7), 1385-1405.

(21) Votano, J. R.; Parham, M.; Hall, L. M.; Hall, L. H.; Kier, L. B.; Oloff, S.; Tropsha, A. QSAR Modeling of Human Serum Protein Binding with Several Modeling Techniques Utilizing StructureInformation Representation. J. Med. Chem. 2006, 49 (24), 7169-7181.

(22) Rowland, M.; Towzer, T. N. Clinical Pharmacokinetics and Pharmacodynamics: Concepts and Applications, 4th ed.; Lippincott Williams \& Wilkins: Baltimore, MD, 2011.

(23) Noulas, A. V.; Theocharis, A. D.; Feretis, E.; Papageorgakopoulou, N.; Karamanos, N. K.; Theocharis, D. A. Pig Vitreous Gel: Macromolecular Composition with Particular Reference to Hyaluronan-Binding Proteoglycans. Biochimie 2002, 84 (4), 295302.

(24) Bishop, P. N. Structural Macromolecules and Supramolecular Organisation of the Vitreous Gel. Prog. Retinal Eye Res. 2000, 19 (3), $323-344$.
(25) Peynshaert, K.; Devoldere, J.; De Smedt, S. C.; Remaut, K. In Vitro and Ex Vivo Models to Study Drug Delivery Barriers in the Posterior Segment of the Eye. Adv. Drug Delivery Rev. 2017, DOI: 10.1016/j.addr.2017.09.007.

(26) Tan, L. E.; Orilla, W.; Hughes, P. M.; Tsai, S.; Burke, J. A.; Wilson, C. G. Effects of Vitreous Liquefaction on the Intravitreal Distribution of Sodium Fluorescein, Fluorescein Dextran, and Fluorescent Microparticles. Invest. Ophthalmol. Visual Sci. 2011, 52 (2), 1111-1118.

(27) Rimpelä, A.-K.; Schmitt, M.; Latonen, S.; Hagström, M.; Antopolsky, M.; Manzanares, J. A.; Kidron, H.; Urtti, A. Drug Distribution to Retinal Pigment Epithelium: Studies on Melanin Binding, Cellular Kinetics, and Single Photon Emission Computed Tomography/Computed Tomography Imaging. Mol. Pharmaceutics 2016, 13 (9), 2977-2986.

(28) Bishop, P. The Biochemical Structure of Mammalian Vitreous. Eye 1996, 10 (6), 664-670.

(29) Bos, K. J.; Holmes, D. F.; Meadows, R. S.; Kadler, K. E.; McLeod, D.; Bishop, P. N. Collagen Fibril Organisation in Mammalian Vitreous by Freeze Etch/rotary Shadowing Electron Microscopy. Micron 2001, 32 (3), 301-306. 